\title{
Vehicle Monitoring System for Accident Detection
}

\author{
Priyanka P. Chaudhari ${ }^{1}$, Dr. R. B. Naik $^{2}$ \\ ${ }^{1}$ ME Software Engineering Student, MIT., Dr. BAM University, Aurangabad, India \\ ${ }^{2}$ Professor, Marathwada Institute of Technology, Dr. BAM University, Aurangabad, India
}

\begin{abstract}
In highly populated Countries just like India, in accidents, people lose their lives due to unavailability of proper medical facilities at the right time. This project senses any accident in the vehicle and intimates pre-programmed numbers like the owner of the vehicle, ambulance, police etc. The Global System for Mobile (GSM) technology is used to send the position of the vehicle as a Short Message Service to those numbers. And also the position of the vehicle can be obtained by the owner of the vehicle or anyone with proper permission by sending a Short Message Service to a number. Most of the companies require keeping track of their vehicles, with this equipment we can keep track of the vehicle by periodically sending Short Message Service and the position of the vehicle is sent by the GSM modem as a SMS to the user. To know the position of the vehicle, the owner sends a request through a SMS. This is received by a GSM modem in the device and processed by the processor and the processor sends command to a Global Positioning System (GPS) module in the device. The GPS module responds with co-ordinates position of the vehicle. This position is sent to the user as a SMS to the user with date, time, latitude and longitude positions. When there is an accident, the accelerometer sensor detects the change in position and sends a signal to the processor. The processor analyses the signal and finds there is an accident. It immediately sends the position of the vehicle and also the information that there is an accident, to preprogrammed numbers such as the owner of the vehicle, police, ambulance etc. So the ambulance arrives in time and the police can arrive in time to clear the traffic. This reduces the time taken by ambulance to arrive and also traffic can be cleared easily.
\end{abstract}

Keywords: GSM, GPS, VTS, GPRS

\section{Introduction}

Now a days number of vehicles are increasing very fast .This is causing high increase the number of road accidents. Due to accidents people are losing there lives. According to the World Health Organization, In a year, approximately 1.2 million people lose their lives. $16 \%$ of the world's road accident deaths are recorded in India, though India contributes only $1 \%$ of the world's road vehicles.

It is due to the increase in the number of vehicles without a successive raise in the road facilities required for it. In most of the accident cases, the sufferers lose their lives because of the unavailability of medical services at the right time. In large companies with a large number of vehicles, the drivers make use of the company's vehicles even for their own purposes and impact a loss to the company. To crack problems like these, this project came into existence. According to this project when a vehicle meets with an accident immediately sensor will detect the signal and sends it to Server. Server sends the alert message through the GSM MODEM[1][2][3][4][5] including the location of the vehicle to police control room and nearby hospitals for ambulance service. Hospitals will get alert message regarding accident through android applications and they pole for conformation for providing ambulance service as soon as possible. So that life of wounded person can be saved. Also police can immediately come after receiving the information and necessary action will be taken.

\section{System Survey}

Existing system is based on call center based(Helpline 108) work and all the process are done manually, so they maintain call $\log$ registers and recording all the details of the system.

Existing system waiting foe call and accurate location of the accident the it take the action. This is very time consuming task.

Existing system not able to make call or massage to victims friends or relative. Due this they not able to reach at hospital to avail special treatment to victim.(i.e. for some cases permission, medicine and money required from keen to hospital administration.)

Exiting system not provide application interface on mobile.

Existing system not confirms whether the help (Ambulance)is coming or not. Else how much far it is \& how much time required.

\section{Objective}

Vehicle monitoring system is used for keeping track of vehicle movements by using client server system. As refer to literature and survey following objective are set to work

In case of any accident,

- To develop a method of accident detection that is efficient

- To send messages to programmed mobile numbers, the owner of the vehicle, Police to clear the traffic, Ambulance to save the people can be informed by this device.

- To develop two android applications. One for customer and another for hospitals. By using clustering algorithm accident notification will be sent to the hospital app with the address for accident.

- To develop polling method for providing ambulance service so that not more than one ambulance will come at a time and this notification will send to customer application.

- To use a GPS [6][7][8][9][10](Global Positioning System) to know the accurate location of the vehicle with an exactness of a few feet. 


\section{International Journal of Science and Research (IJSR) \\ ISSN (Online): 2319-7064}

Index Copernicus Value (2013): 6.14 | Impact Factor (2015): 6.391

- To implement with the different technologies like Controller programming, AT Commands, client server programming and mobile apps under one recognition system.

Based on above objective, we undertaken present application development work.

Vehicle monitoring system [11][12][13][14][15][16][17]for accident detection is consist of following sub systems

1) GPS,GSM \& GPRS Module

2) Application Server

3) Web Interface

4) Mobile App interface for Client \& Hospital

\section{Architectural Design}

Any real world system is used by different users. The users can be developers, testers, business people, analysts and many more. So before designing a system the architecture is made with different perspectives in mind. The most important part is to visualize the system from different viewer's perspective. The better we understand the better we make the system as shown in figure 1 .



Figure 1: Architectural Design for VMS

\section{The System Specific Requirements}

The remaining sections of this document provide a general description, including characteristics of the users of this project, the product's hardware, and the functional and data requirements of the product.

\section{A. Functionality}

Features from vision documents are then refined into use case diagrams and to sequence diagram to best capture the functional requirements of the system.

1. Provide comprehensive User Web Portal. The system shall display user login and able to access view of real time vehicle location.

2. Provide comprehensive Admin Web Portal. The system shall display Admin login and able enter customer/company.

3. Hardware Configured for system shall display all the products which can be configured. The system shall allow user to select the product to configure. Provide comprehensive product details. The system shall display detailed information of the selected products.

4. Maintain customer profile..The system shall allow user to create profile and set his credential. The system shall authenticate user credentials to view the profile. The system shall allow user to update the profile information.

5. Provide personalized profile

The system shall display the detailed information about the selected vehicle information about location.

6. Provide Customer Support.

The system shall provide online help, FAQ's customer support, and sitemap options for customer support..The system shall display the customer support contact numbers on the screen. The system shall display the FAQ's upon request.

7. Online tracking of Vehicle

The system shall allow user to enter the order information for tracking.

The system shall display the current tracking information about the order.

The system shall allow multiple payment methods.

\section{B. Usability}

1. Graphical User Interface: The system shall provide a uniform look and feel between all the web pages.

2. The system shall provide a digital image for each product in the product catalog.

3. The system shall provide use of icons and toolbars.

\section{Accessibility}

1. The system shall provide Web access.

2. The system shall provide Mobile Apps support.

\section{Reliability \& Availability}

1. Back-end Internal Computers: The system shall provide storage of all databases on redundant computers with automatic switchover.

2. The system shall provide RAID V Disk Stripping on all database storage disks using MS SQL.

\section{E. Performance}

1. The product shall be based on web and has to be run from a web server.

2. The product shall take initial load time depending on internet connection strength which also depends on the media from which the product is run.

3. The performance shall depend upon hardware components of the client/customer.

\section{F. Security}

1. Data Transfer: The system shall use secure sockets in all transactions that include any confidential customer information.

2. The system shall not automatically log out all customers after a period of inactivity.

3. The system shall confirm all transactions with the customer's web browser.

4. The system shall not leave any cookies on the customer's computer containing any of the user's confidential information. 


\section{International Journal of Science and Research (IJSR) \\ ISSN (Online): 2319-7064}

Index Copernicus Value (2013): 6.14 | Impact Factor (2015): 6.391

G. Data Storage

1. The customer's web browser shall never display a customer's password. It shall always be echoed with special characters representing typed characters.

2. The system's back-end servers shall never display a customer's password. The Customer's password may be reset but never shown.

3. The system's back-end servers shall only be accessible to authenticated administrators.

4. The system's back-end databases shall be encrypted.

\section{H. Design Constraints}

Standard Development Tools: The system shall be built using a standard web page development tool that conforms to Microsoft's GUI standards.

\section{Interfaces}

1. There are many types of interfaces as such supported by the VMS namely, User Interface, Software Interface and Hardware Interface.

2. The protocol used shall be HTTP.

3. There shall be logical address of the system in IPv4 format.

\section{J. User Interfaces}

The user interface for the software shall be compatible to any browser such as Internet Explorer, Mozilla or Netscape Navigator by which user can access to the system.

\section{K. Hardware Interfaces}

Since the application must run over the internet, all the hardware shall require to connect internet will be hardware interface for the system. e.g. GSM, GPRS.

L. Software Interfaces

1. The VMS shall communicate with the content manager to get the product specifications, offerings and promotions.

2. The VMS system shall communicate with bill Pay system to identify available payment methods, validate the payments and process payment.

3. The VMS system shall deals with critical situation of Vehicle

4. The VMS shall locate Real Time vehicle location.

\section{Context Diagrams}

A context diagram is a graphical representation of the "flow" of data through an information system, modeling its process aspects. A DFD is often used as a preliminary step to create an overview of the system, which can later be elaborated DFDs for designing context which can also be used for the visualization of data processing (structured design).Figure 2 shows what kind of information will be input to and output from the system, where the data will come from and go to, and where the data will be stored.

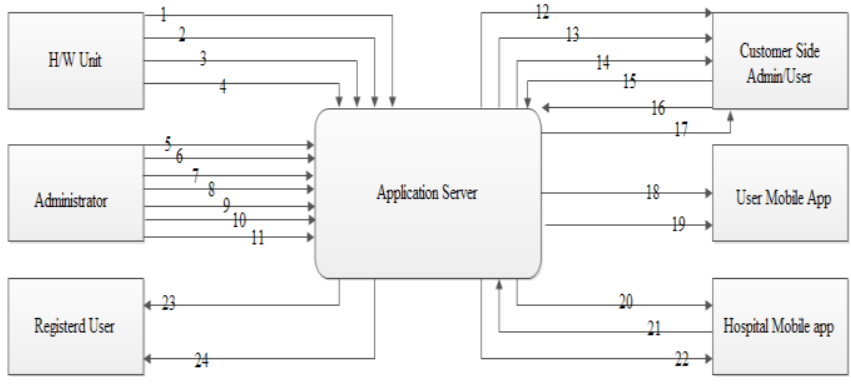

\begin{tabular}{|l|l|}
\hline 1 & Send Received GPS Signal \\
\hline 2 & Send Accident Alert \\
\hline 3 & Send Hardware Status \\
\hline 4 & Send Stop Info \\
\hline 5 & Enroll customer \\
\hline 6 & Enroll Vehicle \\
\hline 7 & Enroll Hardware/Unit \\
\hline 8 & Enroll Supplier \\
\hline 9 & Enroll perches info \\
\hline 10 & Enroll Sale Info \\
\hline 11 & Enroll Product \\
\hline 12 & Track Vehicle \\
\hline 13 & Manage Vehicle \\
\hline 14 & View History \\
\hline 15 & Add profile \\
\hline 16 & Add Geo Fencing \\
\hline 17 & View Report \\
\hline 18 & View dashboard \& Alert \\
\hline 19 & View accident Alert \\
\hline 20 & Send Ambulance Availability \\
\hline 21 & Send Ambulance after Confirmation \\
\hline 22 & Get Accident Massage \\
\hline 23 & Get Victim Hospital Admission Massage \\
\hline & \\
\hline
\end{tabular}

Figure 2: Context Diagram

\section{Algorithm}

1. Accident signal detected.

2. Hardware send signal to server and they are recognized by unique id and location.

3. Identifies the location of the vehicle.

4. And clustering algorithm provides the information about nearest hospitals.

5. Server sends MSG about the accident and its location to programmed numbers.

6. Service call center also get the message on emergency page and it is operated manually.

7. Nearest hospitals get message on their application and then pole for ambulance service with registered ambulance.

8. After ambulance confirmation user/customer can view Root and Time on Google map for getting help.

\section{Implementation}

System Implementation is completed with the help of net and using IIS server. Systems have admin dash board as shown in figure 3. Proper authentication should be there to login the admin portal .Next fields present to login the Admin portal

After Login the admin portal, dashboard page get opened having details of number of customers, Number of vehicles. 


\section{International Journal of Science and Research (IJSR) \\ ISSN (Online): 2319-7064}

Index Copernicus Value (2013): 6.14 | Impact Factor (2015): 6.391

Admin portal contain following left hand side menu: Customer registration, Add Vehicle, Add Product, Purchase form, Sale form, Add unit, Add supplier. On clicking register Customer, Customer registration forms get open. On clicking Add vehicle, Add vehicle form get opened .Here Admin able to add the Vehicles and register it for using the VTS services. On clicking Add product, Add product form get opened .Here Admin able to add the Product .On clicking Add unit, Add unit form get opened .Here Admin able to add the unit and register it for using the VTS services .On clicking Add supplier, Add supplier form should get opened .Here Admin able to add the supplier. On clicking Sale form, sale form get opened .Here admin able to map unit with customer On clicking purchase form, Purchase form get opened .Here admin able to purchase product and map with supplier.

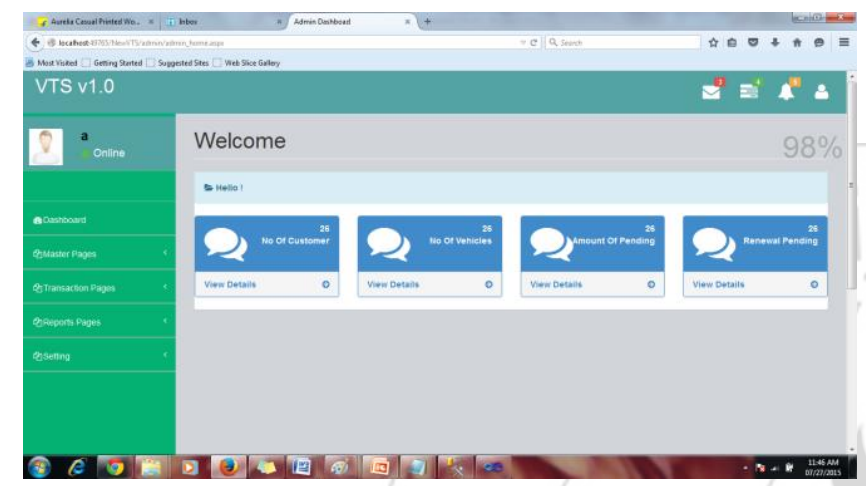

Figure 3: Graphical User Interface for Admin Dash Board

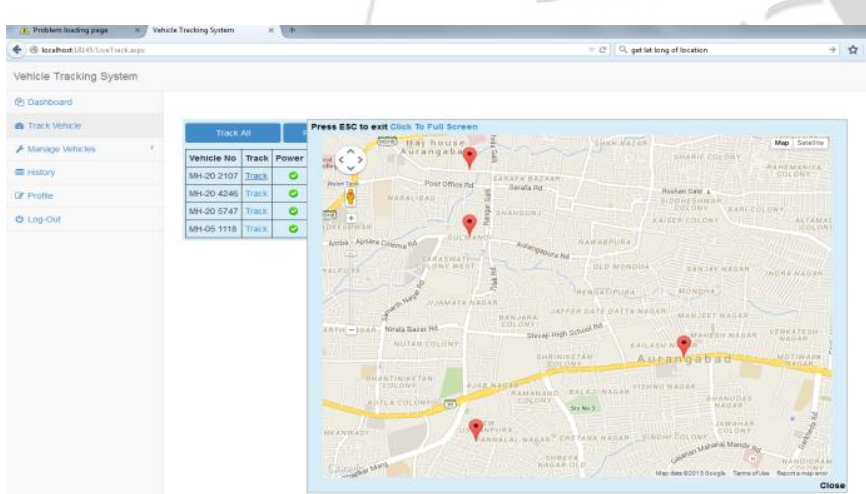

Figure 4: Vehicle Track on Google Map

On clicking track vehicle particular vehicle, all the data of that particular vehicle displayed along with Google map, Vehicle No, Track, Location, Google map showing location of the vehicles as shown in figure 4 .

Geo Fencing is an important feature. User have to just enter the Origin and destination of vehicle then system have to provide an optimised path for that rout, User could modify that path according to his need, still we will find best rout out of it. For this Select vehicle, Enter route, enter date.

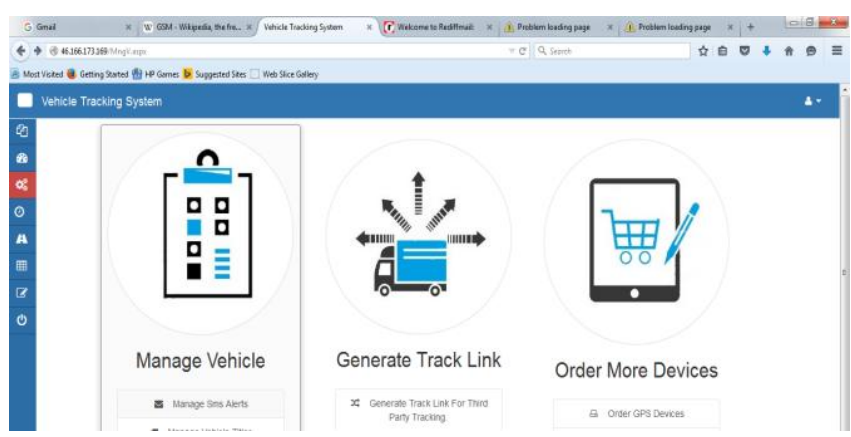

Figure 5: Graphical User Interface for Manage Vehicle

As shown in figure 5 of mange vehicle is used for configuring vehicle and hardware for the system.

\section{Observation And Deployment}

Automobile theft and accidents in the transportation systems have caused significant loss of lives, waste of energy, and loss in productivity. To improve the safety, security and efficiency of the transportation systems and enable new mobile services and applications for the traveling public, the project have been developed, which apply rapidly emerging information technologies in vehicles and transportation infrastructures. It is one of the most challenging and critical issues for the industries. The practical model of this Dissertation will be very efficient, cheaper, and reliable system for security \& safety.

\section{Conclusion}

This application detects Accident and generating message which is informing family members/vehicle owners about the location of accident. This type of application is used for transport management system of Smart City Project in India as well. This application has facility of tracking and Geofencing.We can conclude that the output of this algorithm is gives better results.

\section{Acknowledgement}

In this Paper, I would like to acknowledge who have helped me to complete this paper in presentable manner. But as a matter of tradition I have tried to express it in my simple words. I would humbly like to thank my guide Prof. R.B. Naik for his guidance. Without his help it would not have been possible to reach at this stage.

\section{References}

[1] Flesher P.B. "Design and development of GPS/GSM based vehicle tracking and alert system for commercial intercity buses"IEEE,25 Oct 2012,pp 1-6

[2] C.Prabha, R.Sunitha, R.Anitha "Automatic Vehicle Accident Detection and Messaging System Using GSM and GPS Modem"- International Journal of Advanced Research in Electrical, Electronics and Instrumentation Engineering,Vol1,2010,pp1-5

[3] Pankaj Verma "Design and development of GPS/GSM based tracking System with Google map based monitoring”,IJCSEA,Vol no3 ,June 2013,pp33-40

[4] Montaser N. Ramadan - Intelligent Anti-Theft and Tracking System for Automobiles - International Journal 


\section{International Journal of Science and Research (IJSR) \\ ISSN (Online): 2319-7064}

Index Copernicus Value (2013): 6.14 | Impact Factor (2015): 6.391

of Machine Learning and Computing, Vol. 2, No. 1, February 2012

[5] Pravada P. "Real time Vehicle Locking and tracking system Using GSM and GPS Technology-an anti theft system"IJTES,March2011,Vol2, pp 272-275

[6] Kunal Maurya "Real Time Vehicle Tracking System using GSM andGPS Technology" International Journal of Electronics and Computer Science Engineering pp 1103-1107

[7] T. Krishna Kishore, T.Sasi Vardhan, N.Lakshmi Narayana, „Automobile Tracking Using a Reliable Embedded Data Acquisition Sysytem With GPS and $\mathrm{GSM}^{\mathrm{ee}}$, International Journal of Computer Science and Network Security, VOL.10 No.2, 2010,pp 286-291

[8] M. A. Al-Taee, O. B. Khader, and N. A. Al-Saber,“ Remote monitoring of Automobile diagnostics and location using a smart box with Global Positioning System and General Radio Service," in Proc. IEEE/ACS AICCSA, May 13-16, 2007, pp. 385-388

[9] Tamil, E.M., D.B. Saleh, and M.Y.I. Idris, "A Mobile Automobile Tracking System with GPS/GSM Technology", Proceedings of the 5th Student Conference on Research and Development (SCORED), Permala Bangi, Malaysia, May 2007.

[10]Fan, X., W. Xu, H. Chen, and L. Liu, "CCSMOMS:A Composite Communication Scheme for Mobile Object Management System", 20th International Conference on Advanced Information Networking and Applications, Volume 2, Issue 18-20, April 2006, pp. 235-239

[11]Hsiao, W.C.M., and S.K.J. Chang, "The Optimal Location Update Strategy of Cellular Network Based Traffic Information System", Intelligent Transportation Systems Conference, 2006.

[12] Ioan Lita, Ion Bogdan Cioc and Daniel Alexandru Visan, "A New Approach of Automobile Localization System Using GPS and GSM/GPRS Transmission," Proc. ISSE ' 06, 2006, pp. 115-119.

[13] Wen Leng and Chuntao Shi, "The GPRS-based location system for the long-distance freight", ChinaCom '06, Oct.2006, pp1-5.

[14] Hapsari, A.T., E.Y. Syamsudin, and I. Pramana, "Design of Automobile Position Tracking System Using Short Message Services And Its Implementation on FPGA", Proceedings of the Conference on Asia South Pacific Design Automation, Shanghai, China, 2005.

[15] C. E. Lin, C. C. Li, S. H. Yang, S. H. Lin; C. Y. Lin, "Development of On-Line Diagnostics and Real Time Early Warning System for Automobiles," in Proc. IEEE Sensors for Industry Conference, Houston, 2005, pp. 4551

[16] J. E.Marca, C. R. Rindt,M.Mcnally, and S. T. Doherty, "A GPS enhanced in-Automobile extensible data collection unit," Inst. Transp. Studies, Univ.California, Irvine, CA, Uci-Its- As-Wp-00-9,2000,pp.522-525.

[17] Mohammad A. Al-Khedher "Hybrid GPS-GSM Localization of Automobile Tracking system"International Journal of Computer Science \& Information Technology (IJCSIT) Vol 3, No 6, Dec 2000,pp. 321-328. 